\title{
Refraction as a basis for screening children for squint and amblyopia
}

\author{
R. M. INGRAM \\ From the Kettering and District General Hospital
}

SUMMARY +2.00 to +2.75 dioptres of spherical hypermetropia in the more emmetropic of a pair of eyes is significantly associated with esotropia $(P<0.001)$ and the presence of amblyopia $(P<0.01)$. Anisometropia is not significantly associated with esotropia $(P=0.31)$ unless there is spherical hypermetropia of +2.00 dioptres or more in the more emmetropic eye $(P<0.001)$. Hypermetropic anisometropia of $+1.00 \mathrm{DS}$ or $+1.00 \mathrm{D}$.Cyl. is associated with the presence of amblyopia $(\mathrm{P}$ $<0.001)$. In the absence of esotropia there is also a significant association between the amount of anisometropia and the initial depth of amblyopia $(P<0.01)$. The additional presence of esotropia increases the depth of amblyopia further $(\mathrm{P}<0.05)$ but not the incidence of amblyopia $(\mathrm{P}>0.30)$. The level of significance of the association of refractive errors with squint/amblyopia was itself significantly higher $(\mathrm{P}<0.01)$ than that between a family history of squint or 'lazy eye' on the one hand and squint and/or amblyopia on the other hand. $72 \pm 3 \%$ of all cases of esotropia and/or amblyopia in this sample of children had a refractive error of +2.00 DS or more spherical hypermetropia in the more emmetropic eye, or $+1.00 \mathrm{D}$. or more spherical or cylindrical anisometropia. Since there is a close association between the refraction and how, when, and whether a child presents with squint and/or amblyopia, it would seem reasonable to reconsider refraction as a basis for screening young children for visual defects.

The problems of our present subjective methods of identifying squint, and particularly amblyopia, have been outlined (Ingram, 1977), and it was suggested that an objective method of screening might be better. Kramar (1973) has even suggested that the detection of certain refractive errors might be used to predict the appearance of squint. A study of the literature showed how little has been established about the association of refractive errors with strabismus/amblyopia and the finding that +2.00 to +2.75 dioptres of spherical hypermetropia in the more emmetropic of a pair of eyes was significantly $(P<0.01)$ associated with esotropia in children seen before the age of two years (Ingram, 1973) was surprising.

The purpose of this paper, therefore, is to report the refractions of the sample of children just described (Ingram, 1977). Abnormal amounts of hypermetropia and anisometropia in children are defined and the possibility of refraction as a basis for earlier detection of squint and amblyopia is com-

Address for reprints: Dr R. M. Ingram, Kettering and District General Hospital, Rothwell Road, Kettering NN16 8UZ, Northants. pared with the use of a family history of these conditions.

\section{Methods}

Many of the myopes were refracted without cycloplegia, but all other cases, irrespective of whether they had any defect of visual acuity or possibility of strabismus, and all those referred with 'non-visual' problems were refracted after full cylcoplegia with either $1 \%$ Atropine or $1 \%$ Cyclogyl. The refraction of each eye was obtained after retinoscopy at a working distance of one metre and subtraction of +1.75 dioptres, in each meridian, and recorded in plus spheres and plus cylinders. All refractions have been carried out by the author.

\section{Method used to record the refraction}

Pendse (1954) has drawn attention to the absence of an internationally acceptable method of recording refraction. The method that has been used most commonly is to record the spherical equivalent or the mean of the spherical equivalents of the two eyes. This method, which has been criticised by 
Johnstone and McLaren (1963), is satisfactory for recording broad overall changes in the refraction of large population samples, but it does not allow for enough of the details which are so necessary for this type of investigation.

Therefore the amount of hypermetropia (or myopia) is presented as the spherical refraction of the more emmetropic meridian of the more emmetropic eye. Astigmatism was recorded separately, but up to +1.5 dioptres of astigmatism in the more emmetropic eye has been ignored, and it is accepted that this is open to criticism.

Several methods of recording anisometropia have previously been used. Jampolski et al. (1955) has specifically criticised the use of spherical equivalents. Stevens (1960) distinguished between spherical and astigmatic anisometropia, but used in his summary 'the difference between the meridia with the maximum refractive errors in each eye for deciding the degree of anisometropia', a method also used by Nordlow (1970). The difference between spherical and cylindrical anisometropia has been ignored in other reports (e.g., Killen, 1961, and Jackson, 1964), but it seemed right to record the two types separately, if only because there was a need to clarify what level of each is significantly associated with squint or amblyopia. Horwich (1964) for example queried whether cylindrical anisometropia is really associated with amblyopia. In this study, either $+1.00 \mathrm{D}$. Cyl. or $+1.00 \mathrm{D}$. Sphere difference between the appropriate meridia of the two eyes has been arbitrarily selected as warranting separate recording as anisometropia.

The depth of amblyopia (where possible)

Visual acuity was measured on a Snellen chart or by means of a linear Sheridan-Gardiner test. The corrected visual acuity has not been recorded, because many 3 to 6-year-old children will admit to only $6 / 9$ or $6 / 12$ acuity with a perfectly normal eye. However, the difference between the corrected acuity of the two eyes in one individual can fairly be regarded as the depth of amblyopia. Thus, a child having corrected acuities of $6 / 6$ and $6 / 6$ partly is recorded as having $<1$ line of amblyopia. A child who has a corrected visual acuity of $6 / 6$ and $6 / 9$ or $6 / 9$ partly has been recorded as having $<2$ lines of amblyopia, as would a child who had acuities of $6 / 12$ and $6 / 18$ or $6 / 18$ partly.

All this information was stored in, and subsequently retrieved from, a punch-card system used on the Delcopex machine.

\section{Findings}

All the circumstances when there might be an association between refraction or a family history on the one hand and esotropia and/or amblyopia on the other hand have been analysed. The numbers of children involved and the statistical analysis for each set of circumstances are given and the clinical significance is discussed later. Children presenting for 'non-visual' problems are compared with others in a few instances because in some respects they may be thought to represent the child population at large.

Table 1 Hypermetropia, esotropia, and amblyopia

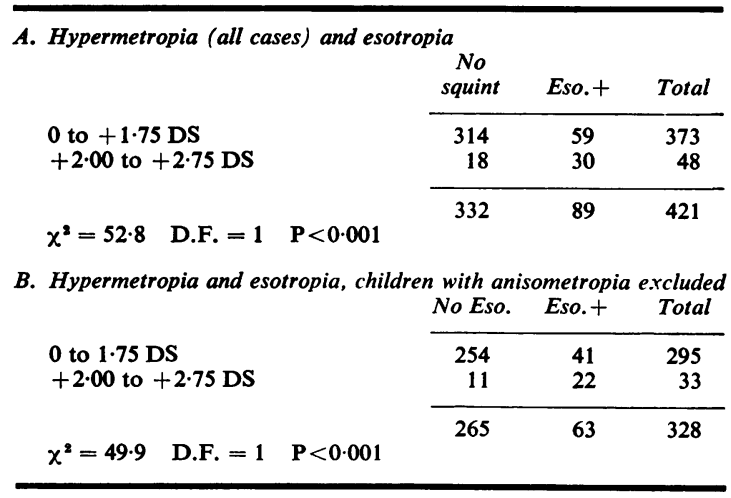

Table 2 Hypermetropia and amblyopia (including children with anisometropia)

\begin{tabular}{|c|c|c|c|}
\hline & $\begin{array}{c}\text { No } \\
A m b .\end{array}$ & $\begin{array}{l}\text { Ambly- } \\
\text { opia }\end{array}$ & Total \\
\hline $\begin{array}{l}0 \text { to }+1.75 \mathrm{DS} \\
+2.00 \text { to }+2.75 \mathrm{DS}\end{array}$ & $\begin{array}{r}226 \\
15\end{array}$ & $\begin{array}{l}87 \\
18\end{array}$ & $\begin{array}{r}313 \\
33\end{array}$ \\
\hline$\chi^{2}=8.88 \quad$ D.F. $=1$ & $0.01>P>0.001^{241}$ & 105 & 345 \\
\hline
\end{tabular}

Table 3 Anisometropia and esotropia

A. Anisometropia (all cases) and esotropia

\begin{tabular}{rrr}
$\begin{array}{c}\text { No } \\
\text { squint }\end{array}$ & Eso. + & Total \\
\hline 421 & 88 & 509 \\
84 & 49 & 133 \\
\hline 505 & 137 & 642
\end{tabular}

$x^{2}=22.87 \quad$ D.F. $=1 \quad P<0.001$

No anisometropia Anisometropia +

B. Anisometropia and esotropia

(excluding children with +2.00 or more D. Spherical hypermetropia in the more emmetropic eye)

\begin{tabular}{|c|c|c|c|}
\hline & $\begin{array}{c}\text { No } \\
\text { squint }\end{array}$ & Eso. + & Total \\
\hline $\begin{array}{l}\text { No anisometropia } \\
\text { Anisometropia, but no hyper- } \\
\text { metropia in 'better eye' }\end{array}$ & $\begin{array}{r}421 \\
65\end{array}$ & $\begin{array}{l}88 \\
19\end{array}$ & $\begin{array}{r}509 \\
84\end{array}$ \\
\hline$\chi^{2}=1.05 \quad$ D.F. $=1 \quad P=0.31$ & 486 & 107 & 593 \\
\hline
\end{tabular}

(Table 3 continued on next page) 
Table 3 (continued)

C. Anisometropia + hypermetropia and esotropia

0 to $+1 \cdot 75 \mathrm{DS}$

$+2.00 \mathrm{DS}$ or more in 'better' eye

\begin{tabular}{ccc}
$\begin{array}{c}\text { No } \\
\text { squint }\end{array}$ & Eso. + & Total \\
\hline 65 & 19 & 84 \\
19 & 30 & 49 \\
\hline 84 & 49 & 133
\end{tabular}

$\chi^{2}=18.20 \quad$ D.F. $=1 \quad P<0.001$

0 to $+1.75 \mathrm{DS}$

$+2 \cdot 00 \mathrm{DS}$ to $+2 \cdot 75 \mathrm{DS}$ in 'better' eye

\begin{tabular}{ccc}
$\begin{array}{c}\text { No } \\
\text { squint }\end{array}$ & Eso. + & Total \\
\hline 65 & 19 & 84
\end{tabular}

Exact probability $\mathbf{0 . 0 2}$

\begin{tabular}{rrr}
7 & 8 & 15 \\
\hline 72 & 27 & 99
\end{tabular}

The initial visual acuity and, therefore, the depth of amblyopia was not known in 27 out of 133 children who presented with anisometropic refractive errors.

There is a quantitative relationship between the amount of anisometropia and the initial depth of amblyopia when the remaining children are considered, e.g.:

\section{Table 5 Anisometropia and depth of amblyopia}

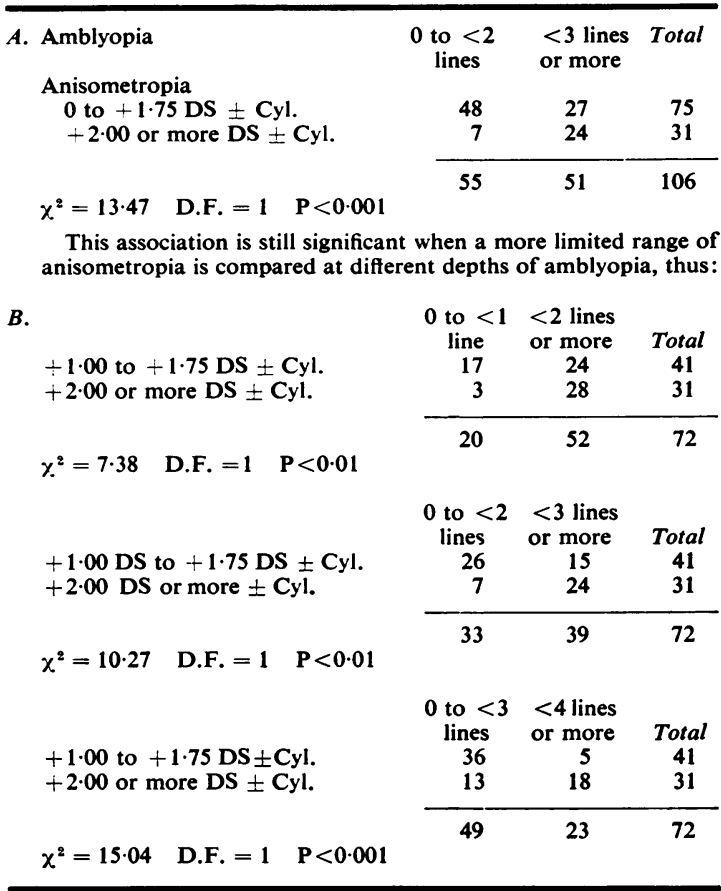

Table 6 Anisometropia, esotropia, and depth of amblyopia

D. Cylindrical anisometropia and presence of amblyopia (children with esotropia excluded)

The association of +1.00 to $+1.75 \mathrm{D}$. Cyl. anisometropia (but no spherical anisometropia) with amblyopia seems apparent, although the number of cases with this limited amount of anisometropia is not sufficient for statistical analysis:
Amblyopia
$0<1<2<3<4<55+$
Anisometropia
No aniso.
+1.00 to +1.75 D. Cyl.
$\begin{array}{rrrrrrr}190 & 11 & 4 & 1 & 1 & 1 & 1 \\ 7 & 5 & 2 & 2 & 1 & 0 & 0\end{array}$

However, there is a statistically significant association between cylindrical anisometropia of $+1.00 \mathrm{D}$. or more (but no spherical anisometropia) and amblyopia (figures taken from Table 7):

No aniso.

+1.00 D. Cyl. or more

\begin{tabular}{rrr}
$\begin{array}{r}\text { No } \\
\text { Amb. }\end{array}$ & Amb. & Total \\
\hline 190 & 19 & 209 \\
10 & 13 & 23 \\
\hline 200 & 32 & 232
\end{tabular}

$x^{2}=35.3 \quad p<0.001$ 
Table 7 Anisometropia (excluding esotropia) and depth of amblyopia

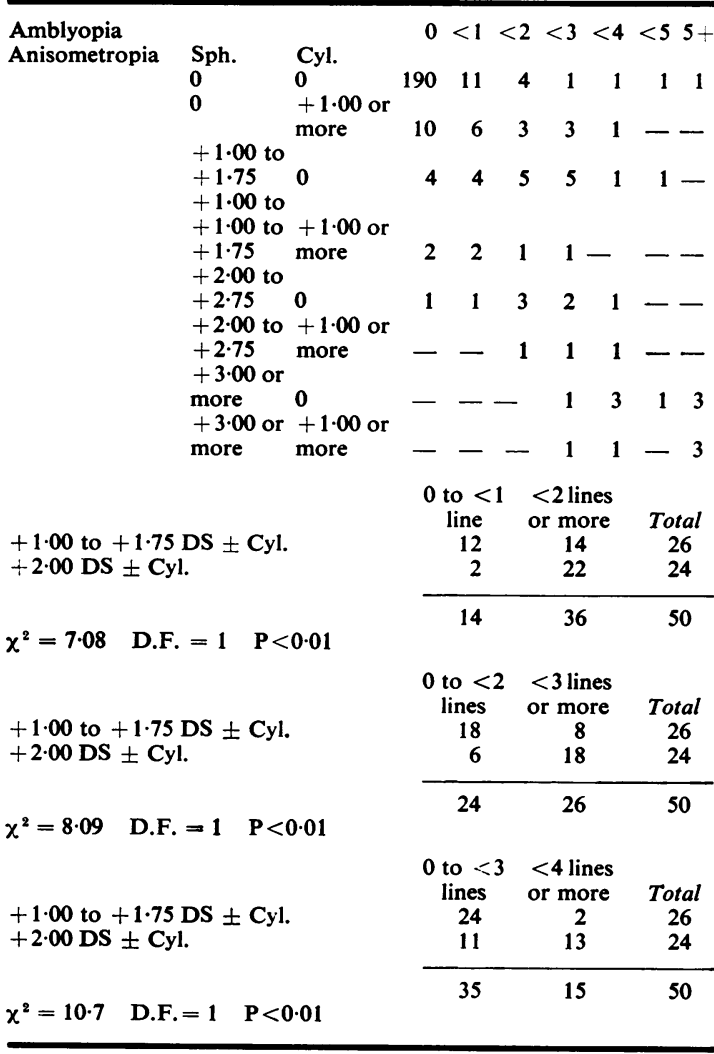

Table 8 Hypermetropia and the age of presentation

\begin{tabular}{|c|c|c|c|}
\hline & $\begin{array}{c}0-4 \\
\text { years }\end{array}$ & $\begin{array}{l}5+ \\
\text { years }\end{array}$ & Total \\
\hline \multirow[t]{2}{*}{$\begin{array}{l}0 \text { to }+1.75 \mathrm{DS} \\
\pm 2.00 \mathrm{DS} \text { or more }\end{array}$} & $\begin{array}{l}22 \\
48\end{array}$ & $\begin{array}{l}37 \\
30\end{array}$ & $\begin{array}{l}59 \\
78\end{array}$ \\
\hline & 70 & 67 & 137 \\
\hline
\end{tabular}

$\chi^{2}=6.96 \quad$ D.F. $=1 \quad P<0.01$

B. Esotropia; hypermetropia and age of presentation $\underset{0-3}{4} 4$ years

\begin{tabular}{ccc}
$\begin{array}{c}0-3 \\
\text { years }\end{array}$ & $\begin{array}{c}4+ \\
\text { years }\end{array}$ & Total \\
\hline 19 & 40 & 59 \\
40 & 38 & 78 \\
\hline 59 & 78 & 137
\end{tabular}

$\chi^{2}=4.239 \quad$ D.F. $=1 \quad P<0.05$

C. Anisometropia; hypermetropia and age of presentation \pm 5 years

\begin{tabular}{ccc}
$\begin{array}{c}0-4 \\
\text { years }\end{array}$ & $\begin{array}{c}5+ \\
\text { years }\end{array}$ & Total \\
\hline 9 & 75 & 84 \\
20 & 29 & 49 \\
\hline 29 & 104 & 133
\end{tabular}

$\chi^{2}=14.72 \quad$ D.F. $=1 \quad P<0.001$
In respect of a family history of squint or 'lazy eye', children presenting with a 'non-visual' problem could be considered as representative of the child population. The incidence of a family history in these children (see Table 10C) is, therefore, compared with the family history of those presenting with visual problems:

Table 9A and B Family history of squint or 'lazy eye'

A. Children presenting with esotropia

\begin{tabular}{rrr} 
F.H.+ & F.H. & Total \\
\hline 79 & 58 & 137 \\
32 & 59 & 91 \\
\hline 111 & 117 & 228
\end{tabular}

$\chi^{2}=10.20 \quad$ D.F. $=1 \quad 0.01>P>0.001$

B. Children presenting with esotropia and/or amblyopia

\begin{tabular}{lrrr} 
& F.H. & F.H. - & Total \\
\cline { 2 - 4 } Esotropia and/or amblyopia & 111 & 98 & 209 \\
Non-visual problem & 32 & 59 & 91 \\
\cline { 2 - 4 } & 143 & 157 & 300
\end{tabular}

$\chi^{2}=7.48 \quad$ D.F. $=1 \quad 0.01>P>0.001$

The incidence of a family history of squint or 'lazy eye' was not significantly different when myopes were compared with children presenting with a 'non-visual' problem $\left(\chi^{2}=0.21 \mathrm{P}>0.50\right)$, although there was a significant difference when myopes were compared with those who had esotropia $\left(\chi^{2}=\right.$ $17 \cdot 16 \mathrm{P}<0.001)$.

Table 9C

C. Children presenting with hypermetropia, hypermetropic astigmatism or anisometropia

Hypermetropic refractive errors Non-visual problem

\begin{tabular}{rrr} 
F.H. & F.H. & Total \\
\hline 104 & 108 & 212 \\
32 & 59 & 91 \\
\hline 136 & 167 & 303
\end{tabular}

$\chi^{2}=4.42 \quad$ D.F. $=1 \quad 0.05>$ P $>0.02$

A family history of parent or sibling wearing spectacles constantly (for any reason) was not significantly associated with children presenting with esotropia $\left(\chi^{2}=1.33 \mathrm{P}>0.20\right)$ or hypermetropia, hypermetropic astigmatism, or anisometropia $\left(\chi^{2}\right.$ $=0.80 \mathrm{P}>0.30$ ), but it was significantly associated in the case of children presenting with myopia $\left(\chi^{2}=5.97 \mathrm{P}<0.02\right)$. 
Table 10 Findings in children who presented with a 'non-visual' problem

A. Presenting diagnosis
Epiphora/naso-lacrimal duct obstruction
Chalazion
Injuries
Keratitis/corneal ulcer (including corneal FBs)
Lid abnormalities (entropion, ptosis. blepharitis, trichiasis,
papilloma)
Conjunctivitis
Dacryocystitis
'Sore eyes'-N.A.D.
Orbital cellulitis
Albinism
Dermoid cyst
Migraine

B. Spherical refraction of the more emmetropic eye 0 to $+1.75 \mathrm{D} . \quad=76 \quad(85 \%)$ Of these,

2 had +1.75 to +2.50 D. astigmatism

5 had spherical anisometropia of +1.00 to $+1.75 \mathrm{D}$.

1 had spherical anisometropia of $>+3.00 \mathrm{D}$., and cylindrical anisometropia of +2.00 to $+2.75 \mathrm{D}$.

2 had cylindrical anisometropia of +1.00 to $+1 \cdot 75 \mathrm{D}$.

+2.00 to +2.75 D. $=8$. +3.00 to +3.75 D. $=2$.

Of these,

1 had spherical anisometropia of +1.00 to $+1.75 \mathrm{D}$.

+4.00 to $+4.75 \mathrm{D}=0$

$5.00 \mathrm{D}$. or more $\quad=1$.

Myopia $\quad=\frac{4}{91}$

C. Family history

40 cases $(44 \%$ of total) had no F.H. whatever of abnormalities.

35 cases (38\% of total) had F.H. of parent or sibling wearing glasses.

32 cases (35\% of total) had some F.H. of strabismus or amblyopia.

6 of the 9 cases of 'significant' anisometropia had a F.H. of parent or sibling wearing glasses or somebody with strabismus or amblyopia.

8 of the 11 cases with 'significant' hypermetropia had a similar F.H.

\section{Discussion}

HYPERMETROPIA, ESOTROPIA, AND AMBLYOPIA +2.00 to $+2 \cdot 75 \mathrm{D}$. of spherical hypermetropia in the more emmetropic of a pair of eyes is significantly (Table 1A, $\mathbf{P}<0.001$ ) associated with esotropia, thus confirming earlier observations (Kramar, 1973; Ingram, 1973), and this is so even in the absence of anisometropia (Table 1B, $P<0.001$ ). It is also significantly (Table $2, \mathbf{P}<0.01$ ) associated with some degree of amblyopia, irrespective of whether esotropia is present. So far as I know, this is the first attempt to define what is an abnormal amount of hypermetropia in a child.
ANISOMETROPIA AND ESOTROPIA

Anisometropia is significantly (Table $3 \mathrm{~A}, \mathrm{P}<0.001$ ) associated with esotropia, but only if cases with spherical hypermetropia of $+2.00 \mathrm{DS}$ or more in the more emmetropic eye are included (see Tables $3 B$ and $3 C$ ). This confirms the original findings of Phillips (1959) but not his more recent ones (Phillips, 1966).

ANISOMETROPIA AND AMBLYOPIA

Two questions require an answer. Firstly, what amount of anisometropia is associated with the presence of amblyopia? Different levels have been quoted in the literature for this, e.g., two dioptres, spherical or cylindrical not stated (Kamiya et al., 1968; Kesby, 1967), 1.5 D. spherical or 1.0 D. spherical and a cylindrical anisometropia (Bishop, 1957), 1.0 D. spherical (Scobie, 1951). Costenbader et al. (1944) simply say that the higher the amount of anisometropia, so the higher is the incidence of amblyopia.

Secondly, what is the relation between the amount of anisometropia and the depth of amblyopia? Lagleyze originally stated that they were roughly proportional to each other. This view has been supported by Copps (1944) and Guzzinati (1957), but it has been questioned by Helveston (1966) and more recently Malik et al. (1968) have stated that the depth of amblyopia is related only to the degree of eccentricity of fixation, this being independent of the amount of anisometropia.

In this sample, taking all cases of esotropia, the added presence of anisometropia is significantly associated with an increased chance that the child will also be amblyopic (Table $4 \mathrm{~A}, \mathrm{P}<0.01$ ). Although the presence of esotropia in addition to anisometropia does not increase the chance of amblyopia being present (Table 4B, P>0.30), it does nevertheless increase the depth of amblyopia when this is present (Table 6A, $P<0.05$ ). If only the lower amounts of anisometropia $(+1.00$ to +1.75 D. sphere \pm Cyl.) are considered, the difference is even more significant (Table 6B, $P<0.01$ ). The additional presence of esotropia, therefore, complicates the association between the amount of anisometropia and the depth of amblyopia.

In this series, taking all those cases without the complicating factor of esotropia, it is clear that +1.00 to $+1.75 \mathrm{D}$. Sphere (Table $4 \mathrm{C}, \mathrm{P}<0.001$ ) or $+1.00 \mathrm{D}$. or more cylindrical anisometropia (Table 4D, $P<0.001$ ) is significantly associated with the presence of amblyopia.

Neither Copps (1944) nor Guzzinati (1957) differentiated between those with and those without a manifest strabismus. Helveston (1966), however, did but the number ( 20 without squint) in his 
series is not sufficient for statistical analysis. Malik et al. (1968) admit that among their cases with central fixation, 'there is a tendency for the visual acuity to be better in cases with a low degree of anisometropia'. Statistical analysis of the figures in Table 1 of their paper, comparing $0-3 \mathrm{D}$. with $3+D$. of anisometropia does show that significantly more of those with the lower level of anisometropia have a visual acuity of $6 / 18$ or better. If a similar calculation is done on all their cases, i.e., those with and those without central fixation, the association is still significant, though less so. Their cases presumably included some with and some without a manifest squint. In this series the number of cases with anisometropia and esotropia is not sufficient for statistical analysis. However, the number of children with anisometropia without esotropia is sufficient for statistical analysis and there is clear evidence that a larger amount of anisometropia is associated with an increased depth of amblyopia (Table 7, $\mathrm{P}<0.01$ ). No record was kept of the fixation of the anisometropic eye in these children, but the fact of the added presence of esotropia further increases the depth of amblyopia (Table 6) could indicate that the fixation pattern is also relevant in determining the depth of amblyopia.

\section{ASTIGMATISM}

No conclusions can be drawn on the clinical significance of hypermetropic astigmatism because there were only eighteen children with $>+1.50 \mathrm{D}$. in the more emmetropic eye in this series. Only one of these eighteen had a squint (divergent); but five of them also had a significant amount of anisometropia, and four of these were known to be amblyopic.

\section{REFRACTIVE ERRORS AND THE AGE OF PRESENTATION}

In this sample, a child with esotropia and/or amblyopia, and found to have +2.00 or more DS in the more emmetropic eye, probably presented before the age of five years (Table 8A $\mathrm{P}<0.01$ ). If he had less than $+2.00 \mathrm{DS}$, he probably presented after the age of 5. A similar relationship holds good if one makes the dividing line for age arbitrarily at 4 years (Table 8B $\mathrm{P}<0.05$ ), but not at 6 years ( $\mathrm{P}<0 \cdot 3)$.

Similar observations can be made in respect of those children who have anisometropia. If such a child presented before the age of 5 years, he was significantly more likely to have +2.00 or more DS of hypermetropia in the more emmetropic eye (Table $8 \mathrm{C} \mathrm{P}<0.001$ ). If he presented at or after the age of 5 the reverse is true.

These observations seem to offer a basis for predicting when ( \pm five years) and how (with or without esotropia, with or without amblyopia) a child with a given refractive error should present under the present system.

\section{IDENTIFYING CHILDREN 'AT RISK'}

It is currently fashionable in paediatrics to identify very young children who are particularly at risk for specific conditions, and investigate or follow them up appropriately. Sheridan (1960) believed that it was impractical to apply vision screening tests to all infants, but nevertheless suggested that we should concentrate on children 'at risk'. Refraction might prove to be a method of identifying these children.

\section{OBJECTIVE METHODS OF SCREENING}

An objective screening test, such as refraction, has been tried before (Hirsch, 1950; Tyser and Letchworth, 1949). The advantages are that it is quick and it can theoretically be applied at any age. Also, at one single screening procedure, it might identify the different types of case currently presenting to the separate 'school' and 'hospital' clinics, i.e., those whose problem will not otherwise be identified until their visual acuity is checked and those whose cosmetic deformity draws attention to there being an abnormality. In this series $72 \pm 3 \%$ of the total of 209 children who were found to have esotropia and/or amblyopia had an abnormal refraction.

\section{FAMILY HISTORY}

A family history (Pratt-Johnson and Lunn, 1967) seems to be the only alternative to the detection of 'significant' refractive errors in very young children. In this series, a family history of squint or 'lazy eye' was present in only $58 \%$ (Table 9A P $<0.01$ ) of cases of esotropia (c.f. Molnar, 1967), and 52\% (Table 9B $\mathrm{P}<0.01$ ) of all cases presenting with esotropia and/or amblyopia.

\section{REFRACTION VERSUS FAMILY HISTORY AS A MEANS OF SCREENING}

The association of refractive errors with esotropia was statistically more significant than the association of a family history with esotropia:

\begin{tabular}{|c|c|c|c|c|}
\hline & & Positive & Negative & Total \\
\hline $\begin{array}{l}\text { Refractive error } \\
\text { Family history }\end{array}$ & & $\begin{array}{l}97 \\
79\end{array}$ & $\begin{array}{l}40 \\
58\end{array}$ & $\begin{array}{l}137 \\
137\end{array}$ \\
\hline$x^{2}=4.89 \quad$ D.F. $=1$ & $P<0.05$ & 176 & 98 & 274 \\
\hline
\end{tabular}

If all children with esotropia and/or amblyopia are considered, the association of refractive errors is 
even more significant than a positive family history:

\begin{tabular}{|c|c|c|c|c|c|}
\hline \multirow{2}{*}{\multicolumn{2}{|c|}{$\begin{array}{l}\text { Refractive error } \\
\text { Family history }\end{array}$}} & & Positive & Negative & Total \\
\hline & & & $\begin{array}{l}152 \\
111\end{array}$ & $\begin{array}{l}57 \\
98\end{array}$ & $\begin{array}{l}209 \\
209\end{array}$ \\
\hline$\chi^{2}=7.47$ & D.F. $=1$ & $P<0.01$ & 263 & 155 & 418 \\
\hline
\end{tabular}

Furthermore, $35 \%$ of those children presenting, in this series, with something other than a 'visual problem' also had a family history of squint or 'lazy eye' (Table 10C). This suggests that if a family history alone was used to identify affected children, one third of all infants would have to be investigated in order to yield approximately half the total number of cases of esotropia and/or amblyopia. These figures are similar to those of Kornder $e t$ al. (1974). By comparison, the search for refractive errors would have to include the whole population, but it might give a higher yield (theoretically $72 \pm$ $3 \%$ ) of those destined to present with squint and/or amblyopia.

Although the ages of the children attending with 'non-visual' problems range from 0 to 15 years, this group might provide an indication of the incidence of hypermetropia or anisometropia in children. $20 \%$ of them (19 out of 91 ) had 'significant' hypermetropia and/or anisometropia. It is just possible, therefore, that $72 \pm 3 \%$ of children with esotropia and/or amblyopia are to be found among $20 \%$ of our child population. For practical purposes, this compares favourably with 50 to $60 \%$ of children with squint and/or amblyopia being selected from $35 \%$ of the population with a positive family history.

On the basis of an overall incidence of $7 \%$ of children having squint or amblyopia, those with a 'significant' refractive error might be calculated to have a 1 in 4 chance of actually having squint/ amblyopia, whereas the child selected on the basis of a positive family history could be calculated to have a 1 in 8.3 chance of being found to have squint/ amblyopia.

It would, incidentally, seem wise to refract under cycloplegia all children who present to an ophthalmologist with a problem other than that of strabismus or amblyopia, since 1 in 5 of them may have a refractive error which is itself worthy of consideration.

SQUINT AND AMBLYOPIA PRESENTING

WITHOUT A SIGNIFICANT REFRACTIVE ERROR $28 \pm 3 \%$ of children who presented in this series with esotropia or amblyopia, or both, had no significant refractive error at the time they presented. Changes in refraction do occur as children grow
(Brown, 1942; Ruskell, 1967; Slataper, 1950), but these changes may not be restricted to a simple increase or decrease in spherical hypermetropia. Therefore, the refraction found at the time a child presents with esotropia or amblyopia does not necessarily represent the situation at the time the esotropia and/or amblyopia were initially established (during the sensitive period?). Previous attempts to link ametropia, especially hypermetropia, with squint and amblyopia in a cause and effect relationship have never been conclusive (see, for example, Chavasse, 1930), perhaps because this simple possibility has not been considered.

\section{Conclusion}

This report demonstrates that the association between hypermetropia and/or anisometropia on the one hand and squint/amblyopia on the other hand is close enough to reconsider refraction as a basis for screening. Fifty years ago Thomson (1924) observed 'the squint is an outward sign-speaking of the majority of cases-that there is a refractive error. Not until the squint occurred, did the parents or doctor know that one eye was defective. ... Our object and ideal should be the correction of the refractive error before the squint occurs. This ideal seems at the present moment impossible to reach on account of the obvious difficulty of examining children of pre-school age'. Is it?

I thank Dr A. Barr for the statistical analyses and Mr A. Stanworth for much helpful criticism.

I also thank our orthoptists, Mrs J. Pyburn and Mrs S. Rogers, for all their help with visual acuities, etc., and Mrs L. Neale for many hours of secretarial work.

\section{References}

Bishop, J. W. (1957). British Orthoptic Journal, 14, 68. Brown, E. V. L. (1942). Archives of Ophthalmology, 28, 842. Chavasse, B. (1930). Transactions of the Ophthalmological Society of the United Kingdom, 50, 168.

Copps, L. A. (1944). American Journal of Ophthalmology, 27, 641 .

Costenbader, F. D., Bair, D., and McPhail, A. (1948). A.M.A. Archives of Ophthalmology, 40, 438.

Guzzinati, G. C. (1957). Bollettino d'Oculistica, 36, 219.

Helveston, E. M. (1966). American Journal of Ophthalmology, 62, 757.

Hirsch, M. J. (1950). American Journal of Optometry, $27,587$. Horwich, H. (1964). American Orthoptic Journal, 14, 99.

Ingram, R. M. (1973). British Orthoptic Journal. 30, 74.

Ingram, R. M. (1977). British Joul nal of Ophthalmology, 61, 4.

Jackson, C. R. S. (1964). British Orthoptic Journal, 21, 106.

Jampolski, A., et al. (1955). A.M.A. Archives of Ophthalmology, 54, 893.

Johnstone, W. W., and McLaren, D. S. (1963). British Journal of Ophthalmology, 47, 95. 
Kamiya, S., et al. (1968). Rinsho Ganka, 22, 90.

Kesby, B. R. (1967). Transactions of the Ophthalmological Society of the United Kingdom, 87, 703.

Killen, B. V. (1961). British Orthoptic Journal, 18, 9.

Kornder, L. D., et al. (1974). American Journal of Ophthalmology, 77, 207.

Kramar, P. O. (1973). British Orthoptic Journal, 30, 66.

Lagleyze. Quoted by Lyle, T. K., in Worth and Chavasse's Squint. Baillière, Tindall and Cox. London. 1950, p. 139.

Malik, S. R. K., Gupta, A. K., and Choudry, S. (1968). British Journal of Ophtha'mology, 52, 773.

Molnar, L. (1967). Klinische Monatsblätter für Augenheilkunde, 150, 557.

Nordlow, W. (1970). Acta Ophthalmologica, 48, 959.

Pendse, G. S. (1954). Refraction and Body Growth. Indian Med. Res. Mem. No. 38.
Phillips, C. I. (1959). British Journal of Ophthalmology, 43, 449.

Phillips, C. I. (1966). British Orthoptic Journal, 23, 57.

Pratt-Johnson, J. A., and Lunn, C. T. (1967). Canadian Journal of Ophthalmology, 2, 50.

Ruskell, F. L. (1967). British Orthoptic Journal, 24, 25.

Scobie, R. G. (1951). American Journal of Ophthalmology, 34, 817.

Sheridan, M. D. (1960). British Medical Journal, 2, 453.

Slataper, F. J. (1950). A.M.A. Archives of Ophthalmology, 43, 466.

Stevens, P. R. (1960). British Orthoptic Journal, 17, 66.

Thomson, W. E. (1924). Transactions of the Ophthalmological Society of the United Kingdom, 44, 238.

Tyser, P. A., and Letchworth, T. W. (1949). British Medical Journal, 2, 1022. 